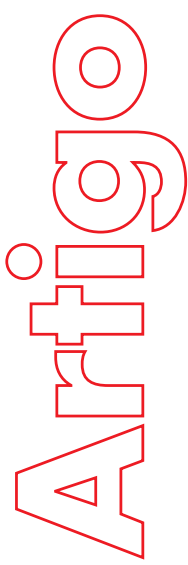

\section{Revista}

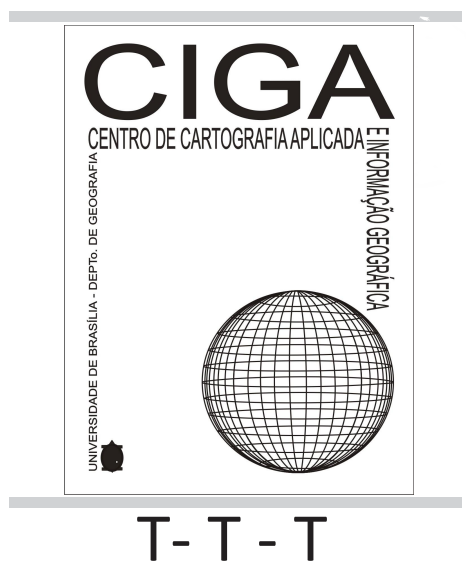

Revista Eletrônica: Tempo - Técnica - Território, V.10, N.2 (2019), 81-99 ISSN: $2177-4366$

\section{AS MATRIZES CULTURAIS AFRICANAS NO VARJAO - DF: TERRITÓRIO E CARTOGRAFIA}

\author{
Yuri Luciano Santos
}

p. 81-99

Como citar este artigo:

Santos Y, L.

AS MATRIZES CULTURAIS AFRICANAS NO VARJÃO - DF: TERRITÓRIO E

CARTOGRAFIA Revista Eletrônica: Tempo - Técnica - Território, v.10, n.2 (2019),p.81-99 ISSN: 2177-4366.

Disponível em: http://periodicos.unb.br/index.php/ciga/

Este obra está licenciado com uma Licença Creative Commons Atribuição - Não Comercial 4.OInternacional. 


\title{
AS MATRIZES CULTURAIS AFRICANAS NO VARJÃO - DF: \\ TERRITÓRIO E CARTOGRAFIA
}

\author{
Yuri Luciano Santos \\ Mestrando em Geografia pela Universidade de Brasília. \\ yurisantos.unb@gmail.com
}

\begin{abstract}
RESUMO: A Geografia afrobrasileira tem sua historiografia marcada pela invisibilidade, desinformação, preconceito e discriminação. A precaridade de estudos das populações africanas no Brasil é uma das barreiras para a plena inserção da matriz africana na sociedade brasileira. Neste sentido, a pesquisa teve como objetivo analisar a espacialização das manifestações culturais de matriz africana na área urbana do Varjão (DF), com o uso de representação cartográfica e registros fotográficos. A partir do trabalho de campo, foram identificadas e mapeadas diversas manifestações culturais de matriz africana, como instituição religiosa afrobrasileira, Capoeira, Escola de Samba e manifestações do movimento Hip Hop produtoras de territorialidades no espaço urbano do Varjão e fortalecendo a identidade territorial da população varjonese, majoritariamente negra As manifestações culturais de matriz africana no Varjão são elementos que promovem territorialidades e socialibilidades de uma porção do espaço vivido e contribui para o empoderamento da população varjonense no que tange ao seu poder de ação, modificação e transformação do seu território. A presença destas manifestações, em muitos casos, estão ligadas à fatores de visibilidade, conhecimento e valorização da cultura africana e afrobrasileira, bem como a luta antirracista, de modo que a manutenção destas manifestações identificadas é de urgência importância para o anseio de uma sociedade justa, igualitária e menos discriminatória.
\end{abstract}

Palavras-chave: Cartografia, Manifestações culturais, Varjão, Territorialidade.

ABSTRACT: The research aimed to analyze the spatialization of cultural manifestations of African matrix in Varjão (DF), using cartographic representation and photographic records. From the fieldwork, several cultural manifestations of African origin were identified and mapped, such as Afro-Brazilian religious institution, Capoeira, Samba School and HipHop movement manifestations that produce territorialities in the urban space of Varjão and strengthen the territorial identity of the Varjonense population. The cultural manifestations of African matrix in Varjão are elements that promote territorialities and socialibilities of a portion of the lived space and contribute to the empowerment of the Varjonense population regarding its power of action, modification and transformation of its territory. The presence of these manifestations, in many cases, is linked to the factors of strengthening, knowledge and appreciation of African and Afro-Brazilian culture, as well as the anti-racist struggle, so that the maintenance of these identified manifestations is of urgent importance for the search for a just society egalitarian and less discriminatory.

Keywords: Cartography, Cultural manifestations, Varjão, Territoriality. 


\section{INTRODUÇÃO}

O Brasil detém a maior população de origem africana fora da África, resultado de quase quatro séculos de uma diáspora negra rumo ao Novo Mundo. O continente africano esteve contido nos diferentes grupos étnicos trazidos para a nação brasileira no período colonial, cada um com suas diferentes crenças, costumes, culinária e, em síntese, suas culturas. Todo este conjunto contido nas matrizes africanas foram um dos pilares da composição da identidade territorial brasileira, embora por muito tempo esta contribuição fosse desvalorizada, deslegitimada e, em alguns casos, criminalizada. É neste sentido que mesmo com a vasta influência das matrizes africanas no território brasileiro, é incipiente o conhecimento sobre a ancestralidade da população de matriz africana.

Segundo Anjos (2010, p.6):

o espaço da cultura africana no Brasil continua sendo uma das suas questões estruturais, que ainda merece investigação, conhecimento e ação, ou seja, alcançar o direito efetivo de uma participação plena na vida nacional. Nesse sentido, as demandas para compreensão das complexidades da dinâmica da nossa sociedade são grandes e existem poucas disciplinas melhor colocadas do que a Geografia e a Cartografia para auxiliar na representação e interpretação das inúmeras indagações desse momento histórico

As interpretações culturais da Geografia privilegiaram, por muito tempo, os gêneros de vida e as descrições das paisagens. Rosendahl \& Corrêa (2003) consideram que uma outra Geografia Cultural, renovada, se estabeleceu valorizando a cultura como um sistema de significações que dão sentido ao mundo e a interpretação dos símbolos culturais que permeiam a relação entre indivíduos e oseu meio. Assim, estudos com pautas diversas e plurais, como feminismo, lutas populares, gênero, etnia/raça e afins ganharam cada vez mais espaço na produção da ciência geográfica. É neste bojo que a Geografia despertou o interesse nas populações com ascendência de matriz africana no Brasil, que tem sua historiografia marcada pela invisibilidade, preconceito e discriminação.

Após séculos de escravidão e da política de embranquecimento da população, a libertação dos povos africanos em condição de escravidão não teve políticas que visassem medidas reparatórias e de integração desta população à sociedade. As elites política e econômica não deram a possibilidade de negros terem acesso à terra, o que pode ser evidenciado na implementação da Lei de Terras de 1850 e na falta de indenizações e reparações para os ex-escravizados. 
A presença do negro no território do Brasil colonial pós-abolição foi de marginalização, uma vez excluso do processo produtivo-ecomônico, restaram as condições precárias de emprego, moradia e salário, então

A população de matriz africana se viu com a necessidade de procurar outras formas de sobrevivência. Nas cidades, aqueles que não tiveram a possibilidade de permanecerem nas regiões centrais foram forçados a ocupar áreas menos privilegiadas do espaço urbano, como várzeas, os morros, as encostas e as periferias distantes onde não havia interesses imobiliários (VILELA, 2013, p.2)

Portanto, colocar em perspectiva geográfica estudos étnico-raciais, questionando o discurso dominante, é uma das formas de combate ao processo histórico e caminhar para uma sociedade justa e igualitária. Ao pensar as populações de matrizes africanas e suas culturas, deve-se considerar as formas de racismo, preconceito, exclusão e as dimensões espaciais destes fenômenos.

A Região Administrativa do Varjão já fora conhecida como uma localidade marcada pela violência, pobreza e exclusão da população negra na Capital Federal. A cidade concentra uma riqueza de manifestações culturais de matriz africana e uma forte identidade territorial justamente por se tratar de um enclave territorial negro em um espaço majoritariamente branco e rico.

Deste modo, o objetivo principal desta pesquisa consiste em compreender a espacialidade das manifestações culturais de matriz africana na área urbana do Varjão. Foram elaborados documentos cartográficos e utilizados registros fotográficos para análise do território.

\section{A REGIÃO ADMINISTRATIVA DO VARJÃO}

A história e ocupação da RA Varjão foi bastante peculiar em relação ao processo de urbanização em Brasília. O Varjão resistiu à estrutura de expulsão dos migrantes de classes empobrecidas para lugares distantes do centro da Capital Federal, no processo de segregação socioespacial planejada (PAVIANI, 2007). O Varjão, região administrativa de baixa renda, configurou-se como enclave social, econômico territorial e racial no centro da Capital Federal (Figura 1).

Sobre a história do Varjão, a CODEPLAN relata que

No final da década de 1950, as terras do Varjão pertenciam à Fazenda do Brejo ou Torto e estavam localizadas no município de Planaltina. O início 
do povoamento da Vila Varjão surgiu na década de 1960, com a chegada das primeiras famílias que vieram desenvolver atividades agrícolas. No começo do ano de 1970, segundo informações de antigos moradores, as pessoas que tinham a posse da área dividiram os lotes entre os empregados, embora a terra fosse de propriedade do GDF (CODEPLAN, 2015).

Segundo Andrade (2004), os primeiros habitantes da então chamada Vila Varjão surgiram na década de 1960, com uma família migrante da Bahia destinada a trabalhar na chácara de um deputado distrital. Após o fim do mandato, o deputado promoveu uma divisão de terras entre seus empregados, que por sua vez, dividiram a terra com seus familiares e parentes e gradativamente novas famílias foram ocupando o local. Assim, de forma desordenada, a comunidade da Vila Varjão se formou por meio de assentamentos de algumas famílias que desenvolviam produções agrícolas de pequeno porte.

Figura 1. Localização da Região Administrativa do Varjão

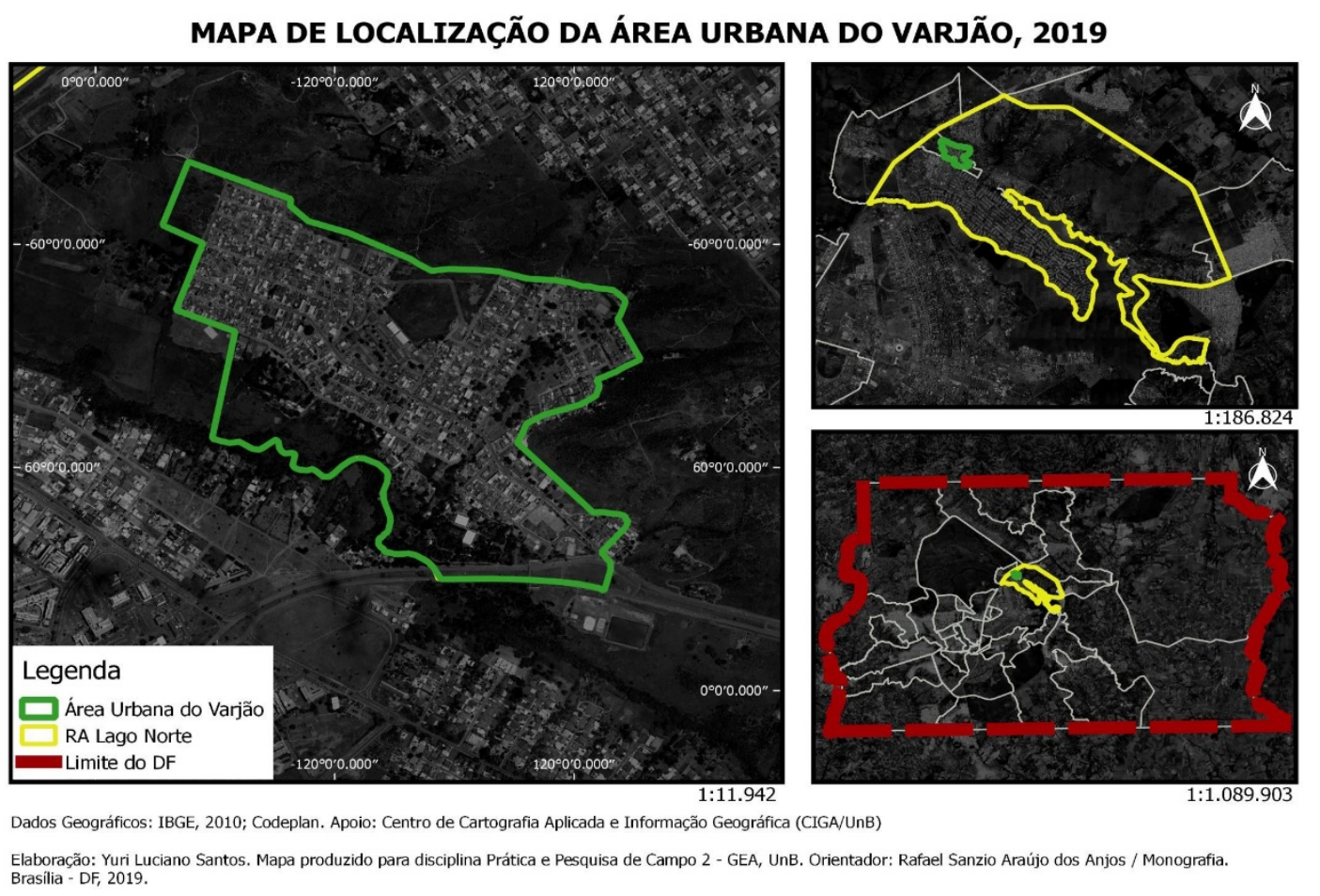

Houve inúmeras tentativas do governo e dos moradores da Região Administrativa do Lago Norte para a remoção dos habitantes da Vila Varjão para outra área do Distrito Federal. Por sua localização geográfica, o local foi alvo de disputas por parte dos moradores de regiões vizinhas das classes altas que visavam valorizar suas propriedades e anexar o terirório da Vila Varjão e desmantelar a incipiente ocupação que se iniciava ali. Houve resistência e união dos moradores da Vila Varjão para que tal fato não ocorresse, algo que fortaleceu a comunidade e afirmou vínculos com sua a terra. (ARAÚJO, 2014). 
Sobre o conluio entre Estado e a classe hegemônica na produção do espaço urbano brasileiro, Campos (2005, p. 77) considera que

O Estado, associado aos interesses das classes dominantes e acionando seu aparelho de repressão, definiu os diversos usos do solo urbano, excluindo parcelas significativas da população. No que diz respeito às classes mais pobres, compostas em sua grande parte por negros (libertos ou fugidos da escravidão), e que já se estabeleciam dentro e fora da cidade legal, no que CHALHOUB (1996) denominou "cidade negra", foram vitimizadas na questão da formação sócio-espacial, impedidas de permanecer por longos períodos em uma parcela do solo urbano.

A população da Vila Varjão aumentou significativamente, de modo irregular e desordenado e, em 1997, foi elaborado outro plano urbanístico que ressaltava a necessidade de concentração dos habitantes com a implementação de novas quadras e incorporação de novos terrenos. Em 2003, a Vila Varjão desmembra-se da RA Lago Norte e se torna uma Região Administrativa independente.

É importante frisar que a RA Varjão está inserida no que Costa \& Peluso (2016) consideram como situação territorial vulnerável, que são territórios fragilizados, estigmatizados e empobrecidos em paramêtros socioeconomicos, políticos e até mesmo da dimensão simbólica da vida. Nos dizeres dos autores:

\begin{abstract}
resultante (concreta e em mutação permanente) das ações que levam à precarização ou à valorização relacionais da vida espacial, é pensada, categorizada e mesmo instituída por meio de comparações, de maneira que o território da vulnerabilidade faz-se para o coletivo como singular e, por vezes, estigmatizado; é encarado como locus da violência, das drogas, da prostituição etc. (COSTA \& PELUSO, 2016, p. 20).
\end{abstract}

Atualmente, segundo dados do PDAD 2018, estima-se uma população urbana de 8.802 pessoas na RA Varjão. Em termos gerais, a população do Varjão é caracterizada por:

- $75 \%$ da população é negra, na soma entre pretos e pardos.

- $24 \%$ dos domicílios são chefiados por mães solteiras

- $51 \%$ da população é formada por imigrantes e, deste montante, $34 \%$ vieram do Estado da Bahia.

- Quanto a escolaridade, 3,5\% da população é analfabeta e 7,9\% tem nível superior, sendo o maior percentual de pessoas com nível fundamental 
incompleto (41\%).

- A população entre 18 a 29 anos que não trabalha nem estuda é de 33,6\%

- No que se refere a população ocupada, $61 \%$ estão no setor de serviços e $24 \%$ no setor de comércio.

- $81 \%$ da população recebe até dois salários mínimos. A renda domiciliar média foi estimada em R $\$ 2.262,9$.

A identidade territorial do Varjão se fortalece na alteridade, da distinção entre seus territórios vizinhos, caracterização que o torna singular no espaço geográfico. Nesse sentido, o Varjão apresenta uma clara a distinção dos processos territoriais entre ela e sua região administrativa imediata - RA Lago Norte. Desde o modo histórico de ocupação do espaço até os aspectos demográficos, culturais, e de hierarquia urbana é possível sustentar que o Varjão tem sua identidade territorial estabelecida na sua singularidade.

A segregação socioespacial evidenciada no Varjão comporta uma singularidade territorial que não está presente nas suas fronteiras, e que não é apenas uma fronteira político-territorial, mas também uma fronteira cultural, econômica e social com, sobretudo, a RA Lago Norte. Assim, a identidade territorial no Varjão estabelece-se pela diferenciação quase antagônica entre a RA e seus limites geográficos.

Conforme já apresentado, apesar da situação territorial vulnerável, a população varjonense buscou formas de territorializar-se no espaço, por meio do pertencimento e da resistência. Não se pode perder de vista que "um território, tido por vulnerável socioeconomicamente, seja representativo da cultura, da identidade ou de uma história local, regional e nacional ou mesmo de afetividades espaciais" (COSTA \& PELUSO, 2016, p. 20).

Composta por uma população de menor renda, com histórico de ocupações. irregulares e demograficamente negra, a história do Varjão é qualificada pela luta dos moradores pela sua terra, produzindo territorialidades que fortalecem o vínculo da comunidade com seu território, onde as manifestações culturais de matriz africana são componentes elementais da formação desta identidade.

\section{CARTOGRAFIA, REPRESENTAÇÃO ESPACIAL E TERRITÓRIO DAS MATRIZES AFRICANAS.}


Com a utilização da representação cartográfica das manifestações culturais de matriz africana no Varjão, foi possível ampliar interpretações e discussões dos resultados obtidos. Uma das constatações primárias é de que as manifestações culturais de matriz africana são elementos produtores de territorialidades no espaço urbano varjonense e de identificação territorial da comunidade com a sua terra.

É importante frisar que o termo mapeamento se refere ao conjunto de entendimentos, leituras e levantamentos sobre o espaço geográfico. Em muitos casos, o mapeamento é lembrado apenas como o mapa temático do tema tratado. O mapa temático é o que permite interpretações iniciais do território estudado, mas ela também possibilita leituras profundas e conjuntas com outros dados espaciais que podem constituir apoio para ordenamento e gestão governamental e fortalecimento das instituições culturais e das manifestações culturais existentes locais (ANJOS, 2010).

A observação da cartografia das manifestações culturais de matriz africana no Varjão indica a diversidade da matriz cultural africana presente na cidade, desde instituição religiosa ${ }^{1}$ afrobrasileira até movimentos urbanos como a cultura Hip Hop, com grafites espalhados nos muros da cidade, passando pela culinária africana, a Capoeira e escola de samba.

A Capoeira e escola de samba Unidos do Varjão foram exemplos de desenvolvimento de manifestos culturais com participação comunitária. Percebeu-se que estas manifestações culturais conquistaram suas próprias referências territoriais na RA junto à administração local e assim puderam desenvolver suas territorialidades. Além disso, a construção de espaços de convivência comunitários permitiram concentrar e dar melhores condições do desenvolvimento das atividades.

\footnotetext{
${ }^{1}$ O Centro Espírita Tenda de Aruanda, instituição religiosa afrobrasileira localizada no Varjão, que consta no Mapeamento dos Terreiros do Distrito Federal de 2018, não teve aprofundamento teórico em respeito à solicitação de entidades cuidadoras do local. Sabe-se, todavia, que nenhum morador do Varjão se declarou praticante de religiões africanas e afrobrasileiras segundo PDAD (Pesquisa Distrital por Amostra de Domicílios) de 2015, feita pela Codeplan. Isto pode indicar que as pessoas praticantes não se declaram em razão das discriminações e intolerância religiosa sofridas pelas instituições religiosas e as pessoas praticantes (PIRES, 2012).
} 


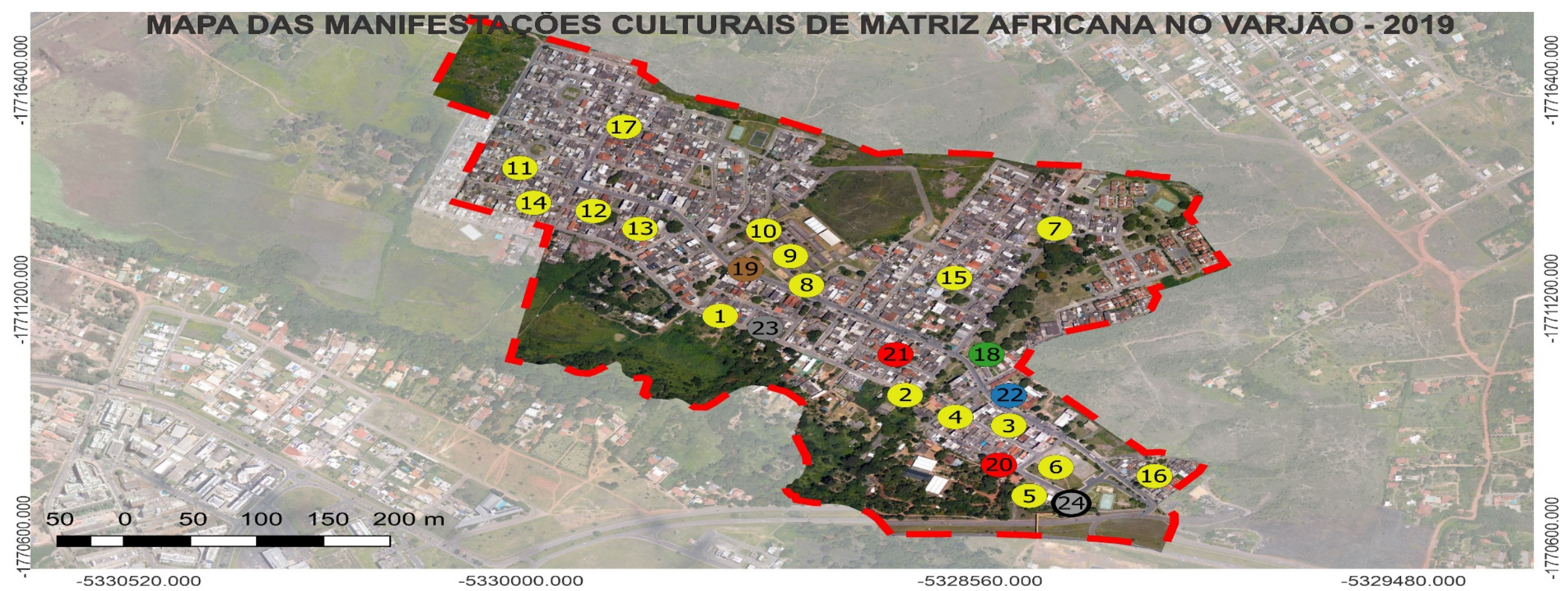

\section{LEGENDA}
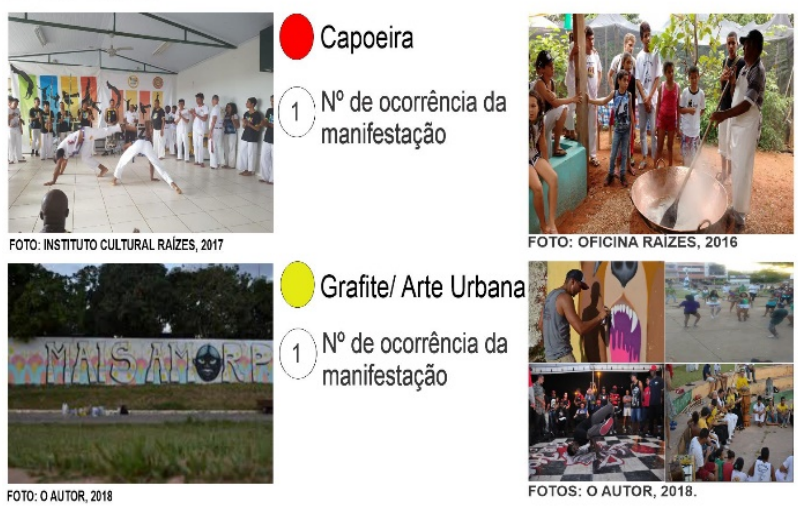

$\mathrm{N}^{0}$ de ocorrência da manifestação

*A Praça Central apresenta manifestações múltiplas, como a Capoeira, atividades da Unidos do Varjão e expressões do movimento Hip Hop Revista Eletrônica: Tempo - Técnica - Território, V.10, N.2 (2019), 81:99 - ISSN: 2177-4366

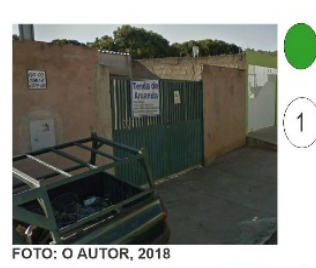

Centro Espirita Tenda de Aruanda

$N^{0}$ de ocorrência da manifestação

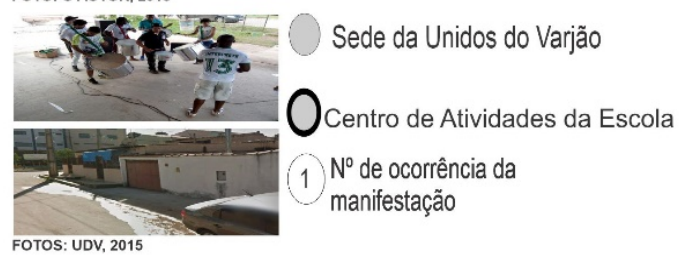

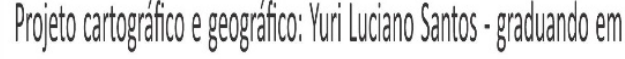

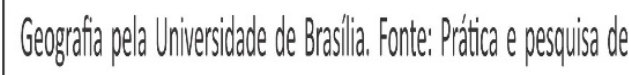

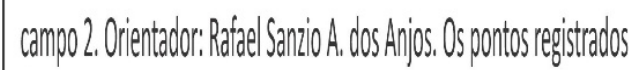

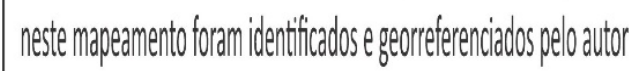

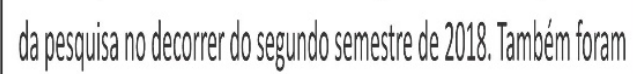
untiliados dados do IBGE e Codeppan para auxillar a produçäo

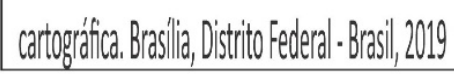


A cartografia das manifestações promove uma visualização significativa do que é produzido culturalmente pela matriz africana e permite várias leituras geográficas da realidade encontrada, a que daremos foco são as territorialidades da matriz cultural africana presente para obter um olhar crítico da relação da comunidade com o seu território a partir das manifestações culturais.

É importanter dizer que este mapeamento não esgota a totalidade das manifestações culturais de matriz africana existentes no Varjão uma vez que a pesquisa não conseguiu chegar em todas manifestações culturais existentes. No relato do Mestre de Capoeira 01, observou-se a existência manifestações culturais relevantes em que a pesquisa não conseguiu esmiuçar:

"O que gente já teve aqui muito forte foi o break, tiveram grupos bem consolidados no Varjão reconhecidos nacionalmente, por exemplo o VBreak que por muitos anos durou no Varjão. O rap e o Hip Hop sempre foram muito forte aqui, até hoje ainda tem alguns grupos, inclusive a galera do grafite, eles fazem ografite e também cantam rap e um deles também foi membro do Vbreak" (Mestre de Capoeira 01, morador local).

\section{A Escola de Samba Unidos do Varjão (UDV)}

Dentre as manifestações identificadas, a Associação Recreativa e Cultural Unidos do Varjão (UDV) destaca-se pela adesão popular e estímulo social que trouxe para a RA, promovendo a integração dos comunidade com o seu espaço habitado por meio de oficinas e atividades culturais em espaços públicos da RA, aproximando à população a percepção de território e territorialidade, uma vez que a RA outrora estigmatizada pela violência, ocupações irregulares e falta de infraestrutura urbana ressignifica-se em atividades culturais que deram a comunidade a oportunidade de ocupar, apropriar e construir o seu espaço vivido.

Constituída 23 de junho em 2009, a UDV tem por objetivos principais o incentivo à cultura, fomento às práticas desportivas, recreativas e socio- educacionais, atividades para a inserção de indivíduos no meio social, diálogos locais, além de participar dos desfiles oficiais de Bloco de Enredo e Escola de Samba. Neste sentido, a Agremiação atua de forma conjunta com a comunidade do Varjão para questões de interesse social, sobretudo aqueles referentes ao âmbito cultural.

Antes de se tornar uma agremiação Carnavalesca, o Varjão contava com um bloco de rua que deu origem a escola, como conta um dos entrevistados da pesquisa: 
"vamos tentar fabricar as peças do bloco, aqui?" Aí a gente começou a trazer de pouquinho em pouquinho a bateria... começava ali na entrada do Varjão e íamos batucando com três, quatro... Ai botava uma caixa, botava um repique. Ai as pessoas começavam a passar e pensar "que som diferente", "chega ai", "ah, deixa eu bater, deixa eu dar um tapa ai" o cara tentava ali na caixa e assim se iniciou (Intérprete da UDV, agente cultural local)

Com isso, a comunidade foi aderindo à ideia de se ter uma escola de samba para o Varjão. O entrevistado, na época de surgimento da escola, buscou fornecer informações sobre o funcionamento e atuação de uma escola de samba para os habitantes do Varjão:

"Saímos daqui mostramos, trazemos todo um conhecimento do que é a escola porque era muito coisa nova para muita gente. Surgiu! Com a magia de 2012 a gente foi campeão e ai startou o nascimento da Unidos do Varjão, de bloco para escola" (Intérprete da UDV, agente cultural local).

Por meio da escola de samba, os moradores do Varjão puderam materializar e constituir um vínculo com o território por eles ocupados e produzidos. A utilização de espaços públicos, a praça, a rua, o Galpão de Eventos que construíram identidades de afeição, solidariedade e pertencimento e um poder simbólico sobre estes espaços, gerando territorialidades. Este sentimento de identificação das pessoas com sua terra pela escola de samba promoveu a construção de mobilização social, pensamento coletivo, de comunidade que motivou a atuação dos sujeitos locais no seu espaço habitado.

As rodas de samba na praça central, as oficinas de samba de gafieira no galpão de eventos, as aulas de percussão para a comunidade, além das apresentações, ensaios e atividades relacionadas ao Carnaval estiveram no cotidiano dos moradores e compuseram a formação de identidade e unidade social na RA Varjão, estabelecendo a relação de que fala Carlos (2001) entre habitante- identidade-lugar.

Os lugares engendram as relações mais próximas entre os indivíduos, manifesta na amizade, laços, solidariedade e interesses em comuns. Para ele, o lugar permite ao mundo a singularização espacial, o aspecto característico, onde os indivíduos dos grupos sociais atuam, materializam, vivenciam seu cotidiano. Quando se soma a noção de lugar uma percepção de poder simbólico onde os sujeitos atuantes se sentem capazes de agir, interagir, transformar o lugar, então temos a construção da territorialidade (SANTOS, 2004). 
Neste sentido, a expressão cultural da escola de samba não somente processos de identidade e pertencimento com o lugar, mas também produz territorialidade na medida em que os próprios habitantes do Varjão são os sujeitos que integram e transformam a produção do espaço urbano.

Sendo caracterizada como uma entidade promotora de atividades sociais regulares e também como integrante das vivências orgânicas da vida cotidiana (HELLER, 1970), a Unidos do Varjão desenvolve projetos sociais voltados para sua comunidade. A escola, desde sua criação, ofereceu diversas oficinas e atividades, comoa instrumentalização e percussão para crianças, jovens e adolescentes. Com recursos próprios, a agremiação desenvolveu aulas de danças na modalidade de samba de gafieira.

A partir de 2015, entretanto, pela falta de incentivos governamentais, não houve desfiles de Carnaval no Distrito Federal e atuação da Unidos do Varjão enfraqueceu na comunidade. A falta de um espaço para acomodação de equipamentos e estruturas da escola também foi outro problema ocorrido, visto que o Galpão de Eventos que era utilizado foi fechado sem muitas explicações pela Defesa Civil, explicou em relato a atual presidente da escola.

Sobre isto, o intérprete da UDV, salienta que a escola necessita de um espaço para desenvolver atividades e oficinas para a comunidade do Varjão, e com a falta de desfiles de Carnaval no DF, a escola passa ter pouco espaço de atuação.

Está sendo um baque muito grande para a comunidade de abandono cultural. A gente entende o momento que o Brasil está vivendo só que eu acho que os governadores e os deputados têm que saber que a economia precisa de incentivos. E a cultura é um dos incentivos da economia. A questão toda de compra de material, de formação de pessoas, de especialização, de tentar tirar um individuo, tentar recuperar uma pessoa (Intérprete da UDV, agente cultural local).

A falta de um espaço físico próprio e de desfiles de Carnaval dificulta a subsistência da escola de samba:

Eu não falo só de dinheiro não, a questão de liberar um espaço, de ajudar na melhoria de um espaço, de poder ajudar na limpeza do espaço, de poder ajudar com a pintura, conservação do espaço. Para trazer mais tranquilidade e paz para esse bairro, ou comunidade pacificada, como já está (Intérprete da UDV, agente cultural local).

O incentivo que escola reivindica, neste sentido, não é apenas financeiro, mas de um território onde possa ser desenvolvido as atividades e oficinas que geram meios para a produção de uma renda própria, como é o caso da ARUC, que produz eventos de rodas de samba em sua sede, aluga o espaço para eventos e é contratada para apresentações 
em várias cidades da Capital Federal

A sustentabilidade da escola parte de investimentos de construção e manutenção de laços comunitários com o público da escola. A produção do Carnaval, os ensaios, a construção de alegorias e adereços, o desenvolvimento de atividades e oficinas para a comunidade e a fidelidade do público da escola só é possível por meio da finalidade maior de uma escola de samba no Carnaval, o desfile.

O desfile de Carnaval representa um fim, o produto final da efetiva participação da comunidade. Entretanto, para que isto ocorra, é necessário ter mecanismos de adesão da população durante o ano inteiro, como atividades, oficinas, festividades e ensaios. Neste sentido, é importante que se tenha uma referência espacial, um território da escola de samba, para que a unificação e o processo das atividades neste território possibilitem a criação de vínculos, pertencimento e identidade com o mesmo que permitirão a manutenção da Unidos do Varjão.

\section{A CAPOEIRA NO VARJÃO}

A capoeira na Região Administrativa do Varjão, assim como no Distrito Federal, começou no espaços públicos urbanos da cidade, pela atuação voluntária de mestres de capoeira. A relação indentária e territorial promovida pela manifestação gerou uma articulação política que culminou em espaço com melhores recursos para o desenvolvimento das atividades, não somente da capoeira, mas de toda cultura produzida na comunidade: a Casa de Cultura do Varjão.

A Casa de Cultura do Varjão é um espaço localizado na entrada da cidade, com amplas salas de música, teatro e dança, além de contar com anfiteatro, varanda e área verde para receber apresentações. Antes da sua construção, a Casa de Cultura foi uma reivindicação antiga por partes dos moradores da cidade e dos artistas locais que utilizam creches e espaços sem cobertura para ensaiar as manifestações artísticas e culturais.

A Capoeira foi uma das manifestações culturais que se apropriou da Casa de Cultura. O Instituto Cultural Raízes, que tem a Capoeira como principal atividade, foi uma das instituições beneficiadas pela abertura do local. Criado em 2007, o instituto realiza projetos sociais, oficinas, eventos e shows culturais com o objetivo principal de promover a cultura popular, principalmente de matriz africana, como ferramentas de educação e socialização. O idealizador do instituto, residente e agente cultural do 
Varjão, relata a história de criação do projeto:

A história do nosso instituto começou com um trabalho voluntário meu, dando aula na rua, nas praças e quadras de esporte e logo a gente estendeu para creches e escolas do varjão mesmo. Isso tudo começou em 2007. De lá pra cá a gente formou monitores que começaram a desenvolver suas próprias aulas e trabalhos. Atualmente o instituto raízes tá no Varjão onde é a nossa sede, a gente regularizou, formalizou como ONG e este é nosso projeto principal. Estamos no Lago Sul e norte também, em creches escolas e temos membros também em São Paulo e Maranhão e Goiás. A partir do Varjão, que foi onde tudo começou (Mestre de Capoeira 01, agente cultural local).

O Instituto começou atuando em espaços públicos de livre circulação do Varjão, onde ganhou adesão dos moradores da cidade e logo se expandiu para espaços com mais recursos, em creches e escolas, que tinham equipamentos como instalações sanitárias, bebedouros, espaços cobertos para desenvolver com qualidade a Capoeira e outras culturas de matriz africana na cidade.

Nesse sentido, a apropriação territorial da Casa de Cultura pelo Instituto representa um polo de vivências sócio-educacionais de matriz africana, uma vez que as atividades desenvolvidas vão além da Capoeira, envolvendo também manifestações como maculelê, maracatu, oficinas de confecção de berimbau, instrumentalização e musicalização. As atividades do instituto acontecem nas segundas, quartas e sextas feiras da semana e envolvem principalmente oficinas de Capoeira, as demais culturas de matriz africana são realizadas de modo esporádico, sem uma frequência definida.

Uma interpretação possível do território, utilizando Holzer (1997), é enxergá-lo como um sistema de lugares em que se constroem vínculos afetivos e identidade cultural de uma determinada coletividade, sendo um espaço aberto ou não, é mister considerar a existência destas territorialidades. Para Holzer, "a territorialidade é melhor compreendida através das relações sociais e culturais que o grupo mantém com esta trama de lugares e itinerários que constituem o seu território" (HOLZER, 1997, p. 56).

Assim, cada coletividade produz uma identidade, fundamentada por instituições que possuam territórios de socialização, onde se constitui uma territorialidade. A Casa de Cultura nesse sentido representa uma territorialidade na medida em que o grupo de Capoeira ali desenvolve seu território, produz suas atividades e práticas e se relaciona com a comunidade.

\section{CULINÁRIAS E HISTÓRIAS AFRICANAS E AFROBRASILEIRA}


O projeto Raízes Africanas foi desenvolvido em 2016 com apoio do Fundo de Apoio à Cultura no DF (FAC) visando trabalhar vivências e técnicas em expressões de origem africana com o objetivo de despertar o sentimento de pertencimento da população do Varjão à cultura africana e afrobrasileira. Foram realizadas, durante o segundo semestre de 2016, oficinas de Capoeira, Barravento, Carimbó, Côco de Roda, Côco de Zambê, Jongo, Maculelê, Maracatu, Puxada de Rede, Samba, Samba de Roda, Yexá, musicalização, instrumentação e visitas a Quilombos. Também houve oficinas de vivências culinárias que consistiam na produção de pratos tradicionais de referência africana feitos pelos próprios participantes da vivência.

O centro cultural Zilda Arns, atualmente denominado de Creche Zilda Arns, foi o local concedido no Varjão para anteder ao projeto, nas palavras da gestora do espaço:

O centro cultural Zilda Arns é uma entidade sem fins lucrativos que funciona no Varjão desde de 1990, e de forma regular e documentada desde 1996. A gente fechou parceria com o projeto Raízes Africanas e foi um prazer aprender sobre raça negra e a nossa cultura e é maravilhoso para a comunidade estar aprendendo sobre nós mesmos. Porque a gente tem que saber por que a gente é negro, o porquê da nossa raça, das nossas comidas, valorizar nossa origem então isso foi uma riqueza imensa para toda comunidade (Gestora da Creche, agente cultural local).

As oficinas eram de acesso público à comunidade de modo que todos os moradores locais tiveram a oportunidade de participar. Foi dada atenção especial sobretudo para os habitantes jovens da cidade. O idealizador do projeto, Mestre de Capoeira, residente no Varjão há mais de 10 anos e também coordenador do Instituto Cultural Raízes considera a RA expressivamente negra, onde a cultura africana e afrobrasileira têm muito significado para a população.

Nas palavras do Mestre de Capoeira 01, havia uma tendência de priorizar projetos e manifestações vindos de outras regiões administrativas em detrimento ao Varjão, o que prejudicava a aderência da comunidade e a criação de vínculos com os projetos:

O que se via antes era muitos projetos e atividades culturais vindo para o Varjão, mas que não eram produzidos por moradores do Varjão, não de entes e agentes culturais da própria cidade. Esse cenário mudou e o projeto raizes africanas foi um exemplo disso, nós fizemos o projeto também no intuito de valorizar o artista local (Mestre de Capoeira 01, morador local).

Já a Mestra de Capoeira entrevistada, também moradora do Varjão, apontou que o projeto contribuiu a ocupação e valorização dos jovens da comunidade: 
que já trabalhavam no Varjão há anos, para melhorar as oportunidades de ocupação dos nossos jovens, essa que é uma área vulnerável, veio para enriquecer mais ainda a cultural afrobrasileira na nossa cidade (Mestra de Capoeira, moradora local).

As atividades de Capoeira foram desenvolvidas junto aos jovens moradores da cidade e aderiu também o ensino sobre musicalização e a instrumentalização do berimbau, pandeiro e atabaques. Nesse sentido, o aluno não somente participava das rodas de Capoeira como também adquiria conhecimentodos processos que fazem o ser da Capoeira. Além das aulas de Capoeira, também eram realizadas aulas de Maculelê e Samba de Roda e as demais manifestações culturais das quais o projeto se propôs a fazer. Para um segundo Mestre de Capoeira entrevistado, as oficinas promoveram um estimulo à identidade afrobrasileira:

Foi um somatório nosso junto com a comunidade que trouxe conhecimento sobre a Capoeira e a cultura negra em geral, tendo em vista que a posição do jovem, a gente sabe, é bem frágil. Então a Capoeira veio para somar e trazer um pouco de cultura, de informação, e reforçar a identidade (Mestre de Capoeira 02, agente cultural)

A Capoeira, naturalmente, foi a manifestação que mais ganhou aderência do público, por se tratar de uma manifestação já conhecida e já praticada pela comunidade do Varjão. Mesmo assim, as demais manifestações culturais representaram uma importante forma de comunicar e valorizar a diversidade de produtos culturais de matriz africana que engendram a formação da identidade afrobrasileira no país. Neste sentido, um dos entrevistados salientou que seu trabalho visou a valorização da cultura pela consideração das várias manifestações existentes:

"Trabalhamos com dança de matrizes africanas, o Maculelê, o Carimbó, Puxada de Rede que a gente faz até hoje. Percussão, trabalhamos com o ritmo também, o próprio Maculelê, o samba-reggae, o Maracatu. Então a gente trabalha com toda cultura popular, principalmente a de matriz africana, no sentido de valorizar ao máximo essa cultura" (Mestre de Capoeira 01, morador local).

As vivências culinárias foram realizadas para que os próprios participantes das oficinas auxiliarem e vivenciarem o preparo de comidas tradicionais africanas. M.A conta que uma das propostas da Oficina Raízes foi "de provocar na comunidade do Varjão a reflexão sobre as suas origens afrodescendentes". Por isso, durante o último sábado de cada mês em que ocorreram as oficinas, houve uma Vivência Culinária, onde participantes das oficinas e comunidade foram chamados a participar do preparo de um prato da cultura africana.

As Vivências Culinárias foram sequenciadas por oficinas de cines debates sobre 
temas afrobrasileiros. Tal atividade visava o debate suscitado através da exibição de filmes, como forma de abrir espaço para diálogos e promover a construção de conhecimento crítico acerca de diversos assuntos da temática negra, como a questão racial, o movimento negro no Brasil, dentre outros.

Um dos cines debates ocorreu com o curta metragem "Mestre Bimba - Capoeira Iluminada”, de 2005, que conta a história de Manoel dos Reis Machado, um vívido nome da Capoeira e criador da Capoeira regional. O filme caminha por uma rica história da herança cultural negra e da Capoeira no Brasil. Deste modo, estas atividades foram promotoras de um desenvolvimento de um olhar crítico e de possibilitar novas leituras de histórias que costumeiramente não são contadas.

Por fim, foram realizadas visitas ao Quilombo do Mesquita, na Cidade Ocidental, estado de Goiás, e na chácara Quilombo dos Palmares. Estas visitas foram promovidas com intuito de consciência e combate ao preconceito e racismo a partir da informação e conhecimento da história do negro no Brasil que ainda carece de reconhecimento e protagonismo na história brasileira.

O Quilombo do Mesquita fica a $50 \mathrm{~km}$ da Capital Federal, onde vivem a quinta geração de remanescentes Quilombolas, com centenários costumes e tradições. Os moradores da comunidade Quilombola tiveram importante papel, apesar de pouco conhecido, na fundação de Brasília.

Atualmente, o mesmo Quilombo enfrenta uma insegurança quanto ao territorial pela expansão do capital e pela valorização das terras na região. Em junho de 2018, a comunidade Quilombola teve de lutar mais uma vez em manter sua identidade e território por conta de uma resolução do Instituto Nacional de Colonizacão e Reforma Agrária (INCRA) em que se aprovara a redução de $80 \%$ de sua extensão territorial ${ }^{2}$.

Pessoas já centenárias ainda vivem na comunidade Quilombola. É por meio deles que se estruturam a relação de identidade com a terra, pela transmissão oral sobre a origem e história da comunidade, que tem registro na Fundação Cultural Palmares e do INCRA. O Quilombo se originou pela herança de terras do fazendeiro José Correia do Mesquita por três mulheres escravizadas.

\footnotetext{
${ }^{2}$ Ver em: https://racismoambiental.net.br/2018/05/25/incra-reduz-em-80-territorio-do-quilombo-mesquita-goiasem-carta-quilombolas-denunciam-pressoes-politicas/. Acesso em 23 abr 2019.
} 
A ideia, também, foi de pôr frente a frente as novas gerações com as gerações antigas, por meio da oralidade dos sujeitos mais antigos da comunidade como forma de uma fonte ancestral e de um resgate histórico dos saberes e conhecimentos da comunidade Quilombola, bem como a valorização da cultura afrobrasileira proporcionado pela troca de experencias e vivências entre os participantes das oficinas.

Outra grande contribuição da oficina se deu com a conscientização dos participantes junto aos Quilombolas, colocando a comunidade do Varjão em contato com informações sobre direitos humanos e da construção da própria cidadania. A perspectiva humana e a formação de cidadãos conscientes de seus direitos e críticos quanto a ausência de políticas públicas afirmativas do Estado Brasileiro foi um ponto importante do projeto.

\section{CONCLUSÕES E RECOMENDAÇÕES}

A cartografia das manifestações culturais de matriz africana no Varjão nos permitiu uma visão ampla e inicial da forma como se espacializa e se comporta a cultura negra nesta Região Administrativa, de população negra e de baixo poder aquisitivo, que pode ser considerada um enclave territorial por estar em espaço rico e predominantemente branco. Esta condição espacial permite ao Varjão reforçar suas territorialidades e identidade cultural, fundamentada na cultura e ancestralidade e africana.

Um ponto importante a ser destacado é o empoderamento comunitário que a cultura de origem africana trouxe para o Varjão, no sentido de que os grupos culturais e os moradores dispuseram de mais caminhos para contribuir com o desenvolvimento da cidade que desejam. As novas construções para realizações de atividades e a utilização de espaços públicos nas manifestações e atividades culturais tiveram uma significativa participação e demanda comunitária no processo, enfatizado o poder comunitário na gestão do seu território.

A presença de expressões culturais africanas no Varjão são sentidas cotidianamente pelos moradores varjonenses e atuam não só no sentido de promover a cultura de matriz e, em alguns casos, o conhecimento sobre o continente africano, mas também contribuir para o combate às desigualdades raciais ao preconceito e o racismo. Nesse sentido o fortalecimento e o desenvolvimento destas manifestações têm um papel fundamental perante à sociedade.

Por fim, mas não finalizando, a partir desta pesquisa as recomendações que surgem, sobretudo destinadas aos setores decisórios e governamentais, são: 
- Manutenção das manifestações e atividades culturais de matriz africana na RA Varjão, visto que a contribuição e o papel desempenhado por estas manifestações são claros no sentido de combate às desigualdades raciais, racismo e preconceito. Não falamos aqui apenas de financiamento, mas também de dar condições mínimas de estrutura para o desenvolvimento das atividades como as produções artísticas e culturais da escola Unidos do Varjão. Um espaço (que já existe) onde possam ocorrer ensaios, reuniões, deposito de equipamentos, etc.

- Ampliação de projetos e oficinas que tratem sobre o continente africano como foi a caso da oficina cultural Raízes Africanas, que cumpriu um papel importante de disseminar conhecimento sobre a África e também promover vivências e experiências nesse sentido. Projetos são benéficos a toda comunidade e podem ser ampliados para escolas do Varjão, visto que a lei 10.639 de 2003 estabelece a obrigatoriedade do ensino de história da África e das culturas africana e afrobrasileiras e esta é uma das formas de continuidade do projeto e da aplicação da lei.

\section{BIBLIOGRAFIA}

ANDRADE, Liza e GOUVÊA, Luiz Alberto de Campos. Vila Varjão: o problema da habitação como uma questão ambiental. In: I Conferência Latinoamericana de Construção Sustentável e 10o. Encontro Brasileiro de Tecnologia do Ambiente Construído. Anais. São Paulo: USP, 2004.

ANJOS, Rafael Sanzio Araújo dos. The Brazilian: population and territoriality. Textos Básicos do CIGA, Brasília, v. 1, n. 1, p. 26-52, 2010.

ARAÚJO, V.S. S. O lugar em "gentrification": a mudança do conteúdo material/ social do Varjão - Distrito Federal; 2014; Trabalho de Conclusão de Curso; (Graduação em Geografia Licenciatura e Bacharelado) - Universidade de Brasília, 2014.

CAMPOS, A. O. DO QUILOMBO À FAVELA. Raça Brasil, Editora Escala, 2005.

CARLOS, A. F. A. Espaço-tempo na metrópole: fragmentação da vida cotidiana. São Paulo: Contexto, 2001.

CODEPLAN / COMPANHIA DE DESENVOLVIMENTO DO DISTRITO FEDERAL. Pesquisa Distrital por Amostra de Domicílios - PDAD. Brasília: SEPLAN - Subsecretaria de Estatística e Informações, 2018. Disponivel em: < http://www.codeplan.df.gov.br/pdad-2018/>

COSTA, E. B.; PELUSO, M. L. Imaginário urbano e situação territorial vulnerável na Capital do Brasil. Biblio3w. v. XXI, p. 1-36, 2016.

HELLER, A. Indivíduo e comunidade - uma contraposição real ou aparente? In: O cotidiano 
e a história. São Paulo: Paz e Terra, $4^{\mathrm{a}}$ ed., 1970, p. 65- 85.

HOLZER, Werther. Uma discussão fenomenológica sobre os conceitos de paisagem e lugar, território e meio ambiente. Revista Território, ano II, n. 3, jul./dez., 1997

PAVIANI, Aldo. Geografia Urbana no Distrito Federal: Evolução e Tendências. Espaço \&

Geografia, v. 10, p. 1-22, abr. 2007.

ROSENDAHL, Z (org). Introdução à Geografia Cultural. Rogério Lobato Corrêa e Zeny Rosendahl. - Rio de Janeiro: Bertrand Brasil, 2003.

SANTOS, Milton. Da totalidade ao lugar. São Paulo: Edusp, 2004. 